\title{
Bond strength and marginal microleakage in restorations photopolymerized with LED and halogen light associated with three application modes of a universal adhesive system: in vitro study
}

\author{
Resistência de união e da microinfiltração marginal em \\ restaurações fotopolimerizadas com LED e luz halógena \\ associadas a três modos de aplicação de um sistema \\ adesivo universal: estudo in vitro
}

Felipe de Brum RICARDI ${ }^{1}$ iD 0000-0001-8355-3038
Mauro Carlos Agner BUSATO ${ }^{1}$ iD 0000-0002-8379-9211
Priscilla do Monte Ribeiro BUSATO ${ }^{1}$ iD 0000-0001-5104-3762
Márcio José MENDONÇA ${ }^{\text {ID }}$ 0000-0002-6953-7135
Saulo Vinicius da ROSA ${ }^{1}$ iD 0000-0002-7107-9575
Paulo Guilherme Bittencourt MARCHI ${ }^{\text {iD }}$ 0000-0002-5726-4803

\section{ABSTRACT}

Objective: This study aimed to assess the bond strength and marginal microleakage in composite resin restorations, using the Single Bond Universal adhesive system associated with Ultralux (halogen) and Bluephase (LED) light curing units. Methods: For bond strength, 80 healthy human third molars were divided into halogen light $(n=40)$ and LED $(n=40)$, and subdivided according to the following application techniques for the adhesive system: etch-and-rinse (enamel), self-etching (enamel), etch-and-rinse (dentin), and self-etching (dentin). The teeth were subjected to the microtensile test and the fracture pattern was observed under an optical microscope at 40X magnification; they were analyzed by ANOVA, and Fisher and Tukey's tests (5\%). For the marginal microleakage test, 120 class II cavities were prepared in 60 healthy human third molars that were randomly divided into halogen light ( $\mathrm{n=30}$ ) and LED $(n=30)$, and subdivided according to the following application techniques for the adhesive system: etch-and-rinse, selective etching, and self-etching. The teeth were thermocycled 2000 times $\left( \pm 5 / 55^{\circ} \mathrm{C}\right)$, stained in $5 \%$ basic fuchsin and sectioned for qualitative and quantitative assessments; they were analyzed by Kruskall-Wallis and Dunn tests (5\%). Results: For the bond strength of enamel and dentin, the adhesive application with prior acid etching was better than self-etching $(p<0.0001)$, regardless of the type of light curing

$\boldsymbol{\nabla} \nabla \boldsymbol{\nabla} \nabla$

1 Universidade Estadual do Oeste do Paraná, Pós-Graduação em Odontologia. Rua Universitária 2069, Sala 84, Jardim Universitário, 85819-110, Cascavel, PR, Brasil. Correspondência para / Correspondence to: FB RICARDI. E-mail: <felipericardi@live.com>.

2 Universidade Estadual Paulista, Campus Araraquara. Araraquara, SP, Brasil.

$\boldsymbol{\nabla} \boldsymbol{\nabla} \boldsymbol{\nabla}$

How to cite this article

Ricardi FB, Busato MC, Mendonça MJ, Rosa SV, Marchi GB. Bond strength and marginal microleakage in restorations photopolymerized with LED and halogen light associated with three application modes of a universal adhesive system: in vitro study. RGO, Rev Gaúch Odontol. 2019;67:e20190031. http://dx.doi.org/10.1590/1981-86372019000313586 
unit $(p<0.05)$. Etch-and-rinse showed the lowest microleakage values $(p<0.0001)$. Conclusion: Etch-and-rinse obtained the best results relative to the other application techniques for the adhesive system in both tests, regardless of the type of light curing unit.

Indexing terms: Dentin-bonding agents. Dentistry. Light-curing of dental adhesives.

\section{RESUMO}

Objetivo: Avaliar a resistência de união e microinfiltração marginal em restaurações de resina composta, utilizando sistema adesivo Single Bond Universal associado com fotoativadores Ultralux (halógeno) e Bluephase (LED). Métodos: Para resistência de união, oitenta terceiros molares humanos hígidos foram divididos: Halógena $(n=40) ; L E D(n=40)$, sendo subdivididos de acordo com a técnica de aplicação do sistema adesivo: condicionamento total-esmalte; autocondicionante-esmalte; condicionamento total-dentina; autocondicionantedentina. Os dentes foram submetidos ao teste de microtração e o padrão de fratura foi observado em microscópio ótico - 40X de aumento, analisadas pelos testes ANOVA, Tukey e Fisher (5\%). Para o ensaio de microinfiltração marginal, 120 cavidades classe II foram preparadas em sessenta terceiros molares humanos hígidos, aleatoriamente divididos: Halógena ( $n=30) ; \quad L E D$ ( $n=30)$ e subdivididos de acordo com a técnica de aplicação do sistema adesivo: condicionamento total; condicionamento seletivo; autocondicionante. Os dentes foram termociclados 2000 vezes $\left( \pm 5 / 55^{\circ} \mathrm{C}\right)$, corados em fucsina básica $5 \%$ e seccionados para avaliações qualitativa e quantitativa, analisados pelos testes Kruskall-Wallis e Dunn (5\%). Resultados: Para resistência de união em esmalte e dentina, a aplicação do adesivo com condicionamento ácido prévio, foi melhor que o autocondicionante $(p<0.0001)$, independentemente do tipo de fotoativador utilizado ( $p<0.05)$. O condicionamento total mostrou os menores valores de microinfiltração, $(p<0.0001)$. Conclusão: O condicionamento total, obteve os melhores resultados em relação às outras técnicas de aplicação do sistema adesivo em ambos os testes, independentemente do tipo de aparelho fotoativador.

Termos de indexação: Adesivos dentários. Odontologia. Aderência dentária por fotopolimerizaçao.

\section{INTRODUCTION}

The appearance of new materials, techniques, or technological discoveries stimulates a paradigm change in the dental practice. The acid etching proposed by Buonocore et al., in 1955, seemed as the only solution for bonding tooth substrates. However, new adhesive systems are constantly being developed to simplify the restorative procedures, optimize the time spent on them, and minimize failures in the complex application of adhesive systems [1].

Enamel acid etching transforms a flat and smooth surface into a highly irregular surface, which results from the dissolution of hydroxyapatite crystals through the selective demineralization of enamel prisms, causing microporosities and increasing the surface area. Enamel bonding is based on the micromechanical retention caused by the introduction and polymerization of resin monomers infiltrated in microporosities, which are produced through the chemical dissolution of hydroxyapatite crystals by phosphoric acid etching [2].

As for dentin, acid etching presents critical points, such as overetching and the formation of fragile areas, as well as the challenge in maintaining optimal dentin moisture. The direct application of adhesives excludes the phase of dentin moisture control after etching, preventing the collapse of collagen fibers when the demineralized dentin is dried out. The application of adhesive to the demineralized dentin with excess water dissolves the adhesive and separates its phase. This was described as "overwet phenomenon" and it compromises bonding to the excessively moist dentin [3].

Self-etch adhesives present a low enamel etching pattern, resulting in lower values of adhesion to enamel. In order to overcome this limitation, selective enamel etching is indicated before using self-etching systems [4].

A new generation of adhesive agents has been called "universal", because they may be used with the techniques of etch-and-rinse, selective enamel etching, or self-etching, depending on clinical specificity and operator preference [5]. From the clinical point of view, this new type of adhesive has been indicated as a solution for the multiple steps required for conventional adhesive systems [6].

Besides adhesive bonding, the complete photoactivation of composite resins is essential, because it relates directly to the physical and mechanical characteristics. The degree of polymerization, in turn, depends on the aspects related to material composition and amount of light provided to the material [7]. An insufficient photoactivation leads to increased water absorption and mechanical compromises including toughness, which may cause fractures, microleakages, and secondary caries. One way of preventing such problems is choosing the best light curing system [8].

There are different light curing units in the dental market, whereas the halogen lamp is the most used. However, despite its common use, such light curing unit presents some deficiencies, such as the limited shelf life 
of halogen lamps (40-100 hours) and the degradation of components (bulb, reflector, and filter) over time, due to the high temperature reached during the procedures [9].

Another option is the use of LED (light-emitting diode) devices, which have over 10,000 hours of shelf life and suffer little productive degradation over time. The LEDs do not require filters to produce blue light, they are resistant to shocks and vibrations, provide minimum heating, and consume little energy during operation [10].

Thus, the present study aims to assess the bond strength and marginal microleakage of restorations photoactivated with LED and halogen light associated with the universal adhesive system, in the following three application modes: etch-and-rinse, selective etching, and self-etching.

\section{METHODS}

The sample was calculated based on probability distributions of the $\mathrm{F}$ family, with repeated family design and interaction within and among the factors. The effect size used was 0.4 , error type 1 (a) of 0.05 , and analysis power of 0.85 , which provided a number of 80 sample units (specimens) for the bond strength variable and 120 for the microleakage variable. The sample was calculated in the GPower software (version 3.1.9.2 - University of Düsseldorf, Düsseldorf). After the approval by the Research Ethics Committee of the Western Paraná State University (PR, Brazil), 140 healthy human third molars were selected and extracted with orthodontic, periodontal, or surgical indication. The teeth were maintained in saline solution for hydration up to one week before use, when they were maintained in $0.5 \%$ chloramine solution for disinfection.

\section{Microtensile assessment}

For the microtensile test in dentin $(n=40)$, all enamel was removed from the teeth. Hence, highrotation \#3100 burs (KG Sorensen, São Paulo, SP, Brazil) under refrigeration were used and changed at every tooth preparation, always starting from the occlusal surface to standardize the smear layer of the restoration area.

For the microtensile test in enamel $(n=40)$, the flatter portion of the teeth was selected among the buccal, lingual, mesial, and distal aspects, so it would be restored from the occlusal surface to the cementoenamel junction. The groups were divided according to figure 1 .

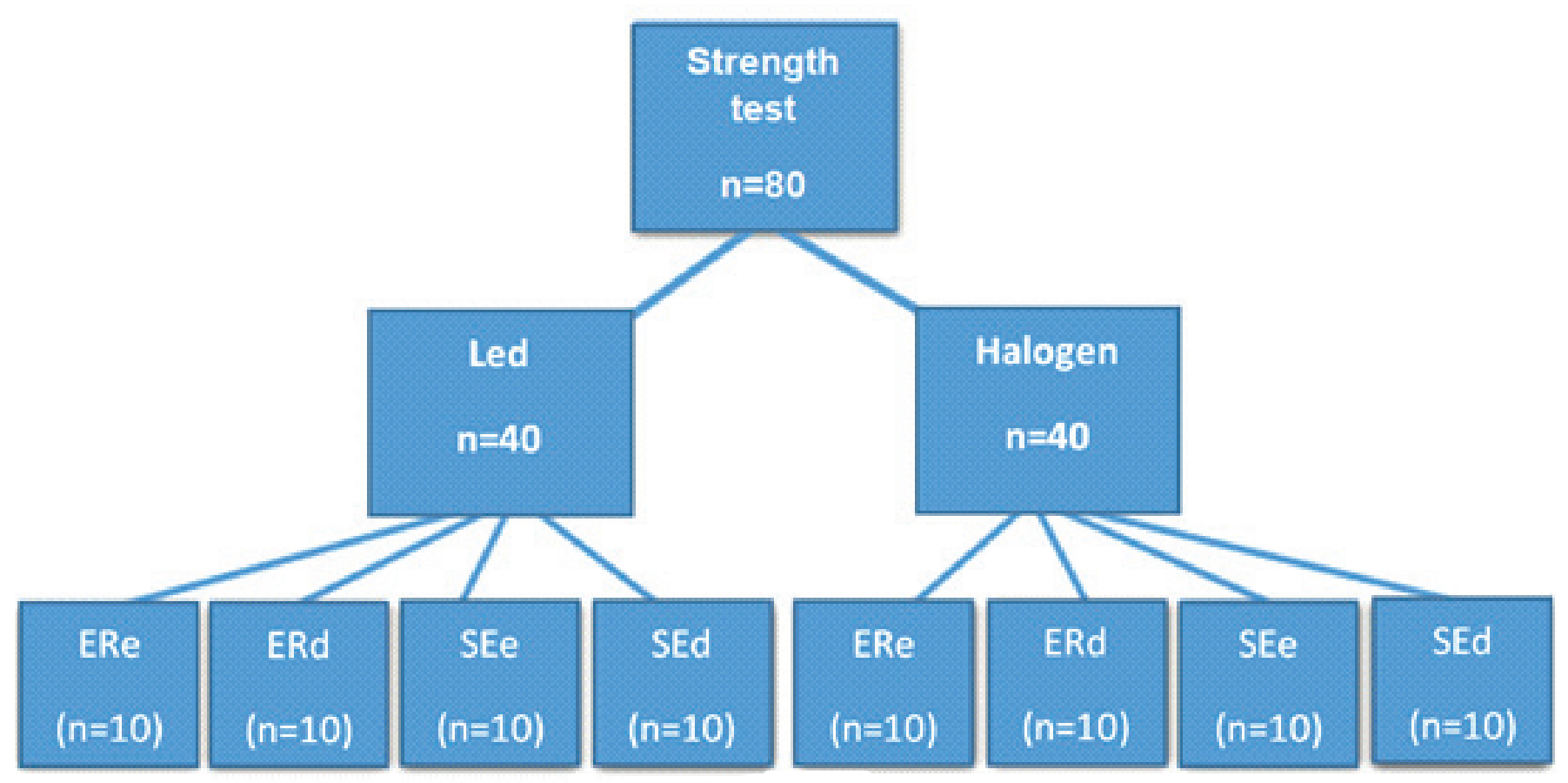

[ERe] Etch-and-rinse - enamel; [SEe] Self-etching - enamel; [ERd] Etch-and-rinse - dentin; [SEd] Self-etching-dentin.

Figure 1. Division of the groups for the bond strength test. 
The surface was treated with the Single Bond Universal adhesive system (3M ESPE, St. Paul, MN, USA) according to the subdivisions mentioned in figure 1 . The adhesive system was applied according to manufacturer's instructions.

The adhesive system was photoactivated with the Ultralux halogen light device (Dabi-Atlante, Ribeirão Preto, SP, Brazil) $\left(600 \mathrm{~mW} / \mathrm{cm}^{2}\right)$ in half of the teeth for 20 seconds and the rest was photoactivated with the Bluephase LED device (Ivoclar Vivadent, Schaan, Liechtenstein) with the High Power software $\left(1200 \mathrm{~mW} / \mathrm{cm}^{2}\right)$ for 10 seconds.

The occlusal surfaces in dentin and the flat surfaces in enamel were restored in two increments of Filtek Z350 resin (3M ESPE, St. Paul, MN, USA) with approximately $2 \mathrm{~mm}$. Photoactivation time was estimated according to the device used, considering 40 seconds for the Ultralux light curing unit (Dabi-Atlante, Ribeirão Preto, SP, Brazil) (Halogen $-600 \mathrm{~mW} / \mathrm{cm}^{2}$ ) in half of the teeth and the rest was photoactivated with the Bluephase unit (Ivoclar Vivadent, Schaan, Liechtenstein) (LED - High Power 1200 $\mathrm{mW} / \mathrm{cm}^{2}$ ) with time reduced to 20 seconds, according to manufacturer's instructions. After restoration, the specimens were stored in deionized water in a $37^{\circ} \mathrm{C}$ stove for 24 hours until sectioning.

The specimens were sectioned at speed of 250 rpm in the buccolingual and mesiodistal directions, in the Labcut 1010 cutting machine (Extec Corporation, London, England) aided by a Labmaster diamond disc (Odeme Dental Research Corporation, Pompano Beach, FL, USA), under constant water irrigation and pressure of $50 \mathrm{~g}$. Sticks of approximately $1.0 \mathrm{~mm}$ of thickness each were obtained and the disc was $0.3-\mathrm{mm}$ thick. The measurement was performed after cutting, aided by a digital specimeter. The sticks obtained had a standard height of $6 \mathrm{~mm}$.

Each stick was positioned with an IC-GEL cyanoacrylate-based adhesive (BSI - Bob Smith Industries Corporation, Atascadero, CA, USA) in a universal testing machine (EMIC Ltda. S. J. dos Pinhais, SP, Brazil). The sticks were secured to the machine aided by a specific device fixed on the base of the machine. A load cell of $200 \mathrm{~kg} / \mathrm{F}$ was used and a tensile force was applied at speed of $0.5 \mathrm{~mm} / \mathrm{min}$ until rupture. The fracture pattern of specimens was also analyzed and classified as adhesive, cohesive, or mixed, in the biological microscope BIO2 (BEL PHOTONICS LTDA, Piracicaba, SP, Brazil) at magnification of $40 X$ [11].

\section{Microleakage assessment (quantitative and qualitative)}

For the microleakage test, 120 class II cavities were made, surrounded by dentin and enamel, with $4 \mathrm{~mm}$ of buccolingual width, $1.5 \mathrm{~mm}$ of standardized depth toward the pulp, and $5 \mathrm{~mm}$ of occlusogingival height ending 1 $\mathrm{mm}$ below the cementoenamel junction. The cavities were assessed with the help of a millimeter probe. The same previously trained operator prepared the cavities using high-rotation \#3100 bur (KG Sorensen, São Paulo, SP, Brazil) under refrigeration, which was changed every four cavity preparations to standardize the smear layer [12]. The groups were divided according to figure 2 .

The surface was treated with the single Bond Universal adhesive system (3M ESPE, St. Paul, MN, USA) according to the subdivisions mentioned in figure 2. The adhesive system was applied according to manufacturer's instructions.

The adhesive system was photoactivated with the Ultralux halogen light device (Dabi-Atlante, Ribeirão Preto, $\mathrm{SP}$, Brazil) $\left(600 \mathrm{~mW} / \mathrm{cm}^{2}\right)$ in half of the teeth for 20 seconds and the rest was photoactivated with the Bluephase LED device (Ivoclar Vivadent, Schaan, Liechtenstein) with the High Power software $\left(1200 \mathrm{~mW} / \mathrm{cm}^{2}\right)$ for 10 seconds.

The cavities were restored with Filtek Z350 composite resin (3M ESPE, St. Paul, MN, USA) in three horizontal increments of around $2 \mathrm{~mm}$ each. A stainless steel matrix band (Injecta Produtos Odontológicos, Diadema, SP, Brazil) was used, coupled to a matrix port (Toflemire, Golgran Ind. e Com. de Instrumental Odontológico LTDA, São Paulo, SP, Brazil) to help producing the samples. The increments polymerized by the Ultralux (Dabi-Atlante, Ribeirão Preto, SP, Brazil) were exposed to light for 40 seconds and the ones photoactivated with Bluephase (Ivoclar Vivadent, Schaan, Liechtenstein) had the time reduced to 20 seconds, according to manufacturer's instructions. The teeth restored were maintained in deionized water in a $37^{\circ} \mathrm{C}$ stove for 24 hours and then the restorations were finished for excess removal, under refrigeration, with diamond burs of the F/FF series \#3100 (KG Sorensen, São Paulo, SP, Brazil). Next, they were washed in an ultrasound tank with deionized water for 10 minutes for residue removal. The same calibrated operator performed all the adhesive and restorative procedures in an acclimatized room with temperature control $\left(20^{\circ} \mathrm{C}\right)$. 


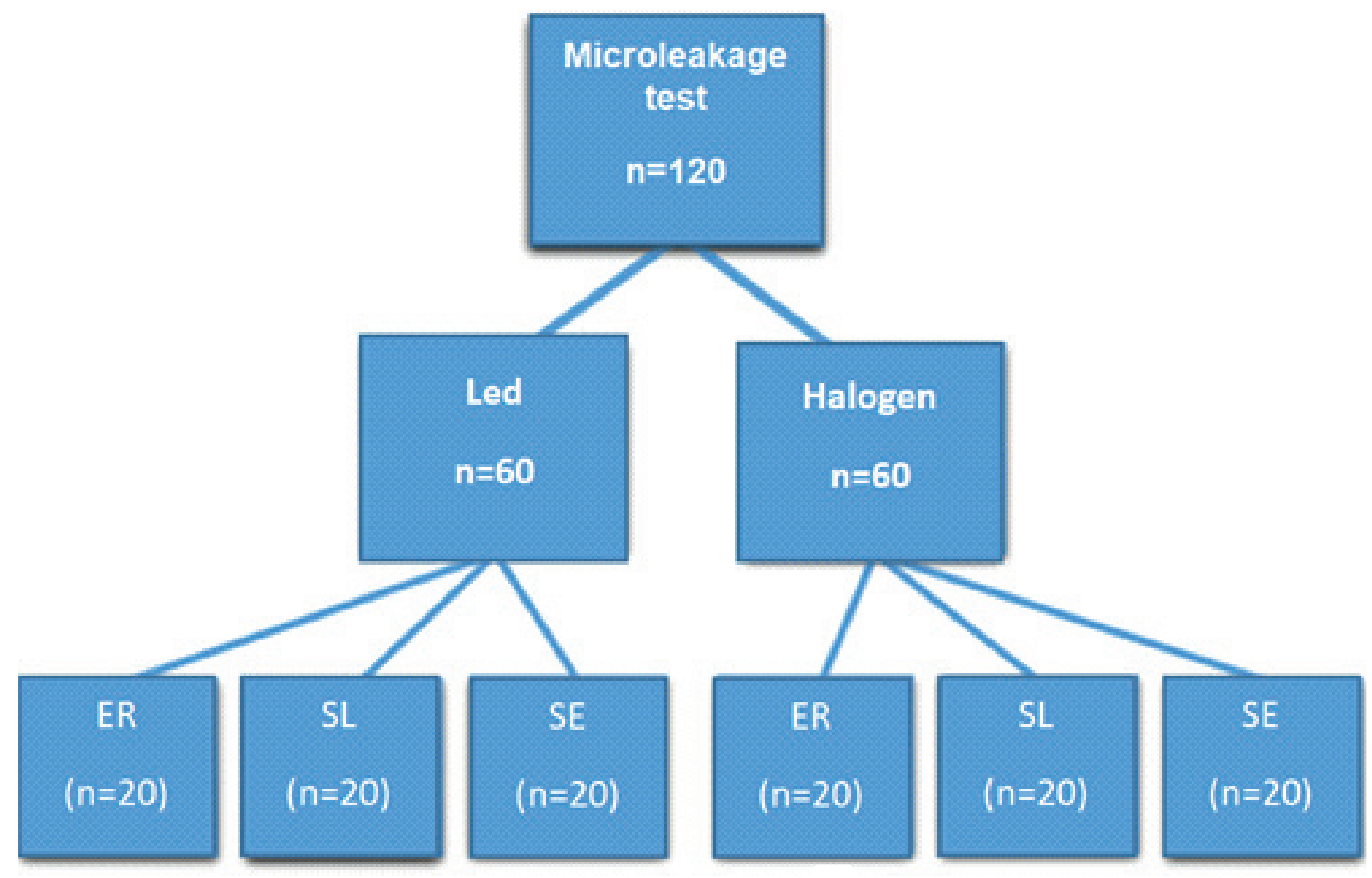

[ER] Etch-and-rinse; [SL] Selective etching; [SE] Self-etching.

Figure 2. Division of the groups for the marginal microleakage test.

Later, the samples were subjected to 2000 cycles between $5 / 55^{\circ} \mathrm{C}$, with 30 seconds of immersion in each bath at a 3-second interval (ISO TR11405) $[13,14]$, to simulate the aging of restorations. After thermal cycling, the teeth were waterproofed with three layers of cosmetic varnish (Colorama, São Paulo, SP, Brazil) up to $1 \mathrm{~mm}$ beyond the restoration margins, and the root apices were sealed with self-polymerizing acrylic resin (Dencrilon - Dencril Resinas Acrílicas, Caieiras, São Paulo, Brazil). After waterproofing, the teeth were rehydrated in deionized water for 10 minutes and then immersed in $5 \%$ basic fuchsin solution for 24 hours. The excess of chemical disclosing agent was removed in running water. The restorations were sectioned longitudinally in the mesiodistal direction by their center, using the Labcut 1010 cutting machine (Extec Corporation, London, England) aided by a Labmaster diamond disc (Odeme Dental Research Corporation, Pompano Beach, $\mathrm{FL}$, USA), at $250 \mathrm{rpm}$, constant water irrigation, and pressure of $50 \mathrm{~g}$, in order to produce two slices. Then, each slice was photographed in a standardized manner with the Canon EOS Rebel XTi camera (Canon Inc., Japan, SN. 2371204627) and the slice with lower photographic quality (brightness, contrast, illumination) was used to assess dye infiltrations [12].

For the microleakage qualitative analysis, scores from 0 to 4 were attributed, allowing to verify the amount of $5 \%$ basic fuchsin penetration in the preparation walls, as follows: 0 - no penetration; 1 - penetration in up to $1 / 3$ of the gingival wall; 2 - penetration in up to $2 / 3$ of the gingival wall; 3 - penetration in the entire gingival wall; and 4 - penetration in the entire gingival and axial walls toward the pulp.

The quantitative assessment was performed by the measurement in $\mathrm{mm}$, using the Image Tool software for Windows 3.0 (UTHSCSA - University of Texas Health Science Center San Antonio) [15].

One single calibrated evaluator read the microleakage scores and classified the fracture patterns. 
However, for obtaining the method error (inter-examiner error), a second experienced evaluator read the images related to both variables. The inter-examiner agreement for the assessment of marginal leakage measured by the Kappa values was considered good regarding the agreement among score classifications (weighted Kappa $=0.815$, at $95 \% \mathrm{Cl}=0.667-0.837$ ). For fracture mode assessment, the agreement was also good (weighted Kappa $=0.802$, at $95 \% \mathrm{Cl}=0.623-0.812$ ).

Before the test applications to the groups, the data were assessed for normality for the variables of bond strength and microleakage (in $\mathrm{mm}$ ), using the D'Agostino test. The bond strength data presented normal distribution, which did not occur for microleakage (quantitative). Therefore, the differences of bond strength in dentin and enamel among the groups were assessed with analysis of variance (ANOVA) and, if required, Tukey's post-test. The factorial analysis of variance was used to distinguish the role of adhesive application mode and type of light curing unit from the influence on bond strength, as well as the interaction of such variables. The analysis of variance test (Kruskall-Wallis) and, if required, Dunn's post-test were used to detect microleakage differences among groups (quantitative). The Kruskall-Wallis test and, if required, Dunn's post-test were used to assess marginal leakage (qualitative). Fisher's exact test was used for the intergroup comparisons of fracture pattern and, when detecting differences, the partition analysis was applied. The comparisons were performed with the BioStat 5.3 software (Instituto Mamirauá, Belém, Pará, Brazil) at 5\% significance level.

\section{RESULTS}

\section{Microtensile results}

Tables 1 and 2 describe the arithmetic mean and standard deviation of bond strength (BS) on enamel and dentin.

The BS group comparison by ANOVA followed by Tukey's post-test, for dentin, showed statistically significant difference among the groups $(p<0.0001)$ and the application of adhesive with the etch-and-rinse technique was better than self-etching, regardless of the type of light curing unit. The factorial analysis of variance results showed that only the adhesive application mode affected

Table 1. Descriptive and inferential statistics of dentin and enamel bond strength, in MPa.

\begin{tabular}{|c|c|c|c|c|}
\hline & $\begin{array}{c}\text { Etch-and-rinse } \\
\text { Halogen } \\
(n=10)\end{array}$ & $\begin{array}{c}\text { Etch-and-rinse } \\
\text { LED } \\
(n=10)\end{array}$ & $\begin{array}{l}\text { Self-etch } \\
\text { Halogen } \\
(n=10)\end{array}$ & $\begin{array}{c}\text { Self-etch } \\
\text { LED } \\
(n=10)\end{array}$ \\
\hline Dentin & $\begin{array}{c}47.3389 \mathbf{A} \\
\pm 8.13\end{array}$ & $\begin{array}{c}47.2387 \mathbf{A} \\
\pm 7.33\end{array}$ & $\begin{array}{c}25.5113 \text { В } \\
\pm 6.81\end{array}$ & $\begin{array}{c}27.5329 \mathrm{~B} \\
\pm 8.01\end{array}$ \\
\hline Enamel & $\begin{array}{c}36.3789 \text { в } \\
\pm 6.75\end{array}$ & $\begin{array}{c}45.6544 \mathbf{A} \\
\pm 7.67\end{array}$ & $\begin{array}{c}21.2699 \mathrm{C} \\
\pm 9.45\end{array}$ & $\begin{array}{c}15.9245 \text { B } \\
\pm 5.12\end{array}$ \\
\hline
\end{tabular}

Note: Different letters indicate statistically significant differences $(p<0.05)$. At least one equal letter indicates statistical similarity $(p>0.05)$.

Table 2. Descriptive and inferential statistics of dentin and enamel fracture patterns, in percentage.

\begin{tabular}{|c|c|c|c|c|c|c|c|c|}
\hline & $\begin{array}{l}\text { Etch-and-rinse } \\
\text { dentin } \\
\text { Halogen } \\
(n=10)\end{array}$ & $\begin{array}{l}\text { Etch-and-rinse } \\
\text { dentin } \\
\text { LED } \\
(n=10)\end{array}$ & $\begin{array}{l}\text { Self-etch } \\
\text { dentin } \\
\text { Halogen } \\
(n=10)\end{array}$ & $\begin{array}{l}\text { Self-etch } \\
\text { dentin } \\
\text { LED } \\
(n=10)\end{array}$ & $\begin{array}{l}\text { Etch-and-rinse } \\
\text { enamel } \\
\text { Halogen } \\
(n=10)\end{array}$ & $\begin{array}{c}\text { Etch-and-rinse } \\
\text { enamel } \\
\text { LED } \\
(n=10)\end{array}$ & $\begin{array}{l}\text { Self-etch } \\
\text { enamel } \\
\text { Halogen } \\
(n=10)\end{array}$ & $\begin{array}{c}\text { Self-etch } \\
\text { enamel } \\
\text { LED } \\
(n=10)\end{array}$ \\
\hline Cohesive & $41.6 \mathbf{A}$ & $41.1 \mathrm{~A}$ & 25.6 B & 22.8 B & $28.5 \mathrm{~A}$ & $29.2 \mathrm{~A}$ & $18.4 \mathbf{A}$ & $10.5 \mathrm{C}$ \\
\hline Mixed & 47.2 & 44.1 & 53.8 & 54.2 & 45.2 & 56.2 & 47.3 & 44.7 \\
\hline Adhesive & 11.1 & 14.7 & 20.5 & 22.8 & 23.8 & 14 & 31.5 & 39.4 \\
\hline Pre-test failure & 0 & 0 & 0 & 0 & 0 & 0 & 2.6 & 5.2 \\
\hline
\end{tabular}

Note: Different letters indicate statistically significant differences $(p<0.05)$. At least one equal letter indicates statistical similarity $(p>0.05)$. 
significantly the bond strength values $(p<0.0001)$, while the type of light curing unit $(p=0.6653)$ and the interaction between application mode and type of light curing unit $(p=0.6937)$ did not affect the BS result for dentin.

The BS group comparison by ANOVA followed by Tukey's post-test, for enamel, showed statistically significant difference among the groups $(p<0.0001)$ and the application of adhesive with the etch-and-rinse technique and LED light curing unit achieved the best BS results $(p<0.05)$. The factorial analysis of variance results showed that only the adhesive application mode $(p<0.0001)$ and the interaction between application mode and type of light curing unit $(p=0.0039)$ affected significantly the BS values, while the type of light curing unit $(p=0.5865)$ did not affect the BS results for enamel.

\section{Fracture pattern results}

Table 3 describes the fracture patterns for dentin and enamel.

The fracture pattern group comparison for dentin showed statistically significant difference among the groups ( $p=0.0163$ ) and the etch-and-rinse groups showed more cohesive failures than the self-etching groups. In contrast, adhesive fractures prevailed in the self-etching groups, regardless of the type of light curing unit.

For enamel, there was a statistically significant difference among the groups $(p=0.0001)$ and the etch-and- rinse groups showed more cohesive failures than the selfetching groups. Adhesive fractures and pre-test failures prevailed in the self-etching groups, especially when using the LED light curing unit.

\section{Marginal microleakage results (qualitative)}

Table 4 shows the medians of marginal leakage scores.

The marginal leakage group comparison (scores) showed statistically significant difference among the groups $(p<0.0001)$ and the self-etching adhesive application mode presented more marginal leakage than etch-and-rinse, especially when such adhesive application mode was used with the halogen light curing unit (median 3). The groups with selective etching of the adhesive system presented intermediate results and, from the statistical point of view, they were similar to the other two application modes tested, except for the results of the halogen-self-etching group and the LED-selective etching group, which showed statistical difference among the groups $(p<0.05)$.

\section{Marginal microleakage results (quantitative)}

Table 5 shows the means and standard deviations of marginal leakage in millimeters.

Table 3. Descriptive and inferential statistics of marginal leakage (median and interquartile deviations of scores).

\begin{tabular}{|c|c|c|c|c|c|c|}
\hline & $\begin{array}{c}\text { Etch-and-rinse } \\
\text { Halogen } \\
(n=20)\end{array}$ & $\begin{array}{c}\text { Etch-and-rinse } \\
\text { LED } \\
(n=20)\end{array}$ & $\begin{array}{l}\text { Selective etching } \\
\text { Halogen } \\
(n=20)\end{array}$ & $\begin{array}{c}\text { Selective etching } \\
\text { LED } \\
(n=20)\end{array}$ & $\begin{array}{l}\text { Self-etch } \\
\text { Halogen } \\
(n=20)\end{array}$ & $\begin{array}{l}\text { Self-etch } \\
\qquad \begin{array}{c}\text { LED } \\
(n=20)\end{array}\end{array}$ \\
\hline Median & $2 \mathrm{BC}$ & $2 \mathrm{~B}$ & $3 A B$ & $2 \mathrm{BC}$ & $3 \mathrm{~A}$ & $3 A C$ \\
\hline Interquartile deviation & 0 & 1 & 1 & 0.5 & 0 & 1 \\
\hline
\end{tabular}

Note: Different letters indicate statistically significant differences $(p<0.05)$. At least one equal letter indicates statistical similarity $(p>0.05)$.

Table 4. Descriptive and inferential statistics of marginal leakage (mean and standard deviation in $\mathrm{mm}$ ).

\begin{tabular}{|c|c|c|c|c|c|c|}
\hline & $\begin{array}{c}\text { Etch-and-rinse } \\
\text { Halogen } \\
(n=20)\end{array}$ & $\begin{array}{c}\text { Etch-and-rinse } \\
\text { LED } \\
(n=20)\end{array}$ & $\begin{array}{l}\text { Selective etching } \\
\text { Halogen } \\
(n=20)\end{array}$ & $\begin{array}{c}\text { Selective etching } \\
\text { LED } \\
(n=20)\end{array}$ & $\begin{array}{l}\text { Self-etch } \\
\text { Halogen } \\
(n=20)\end{array}$ & $\begin{array}{l}\text { Self-etch } \\
\text { LED } \\
(n=20)\end{array}$ \\
\hline Arithmetic mean & $1.278 \mathrm{BCD}$ & $0.923 B D$ & $1.744 A C D$ & $1.693 B C D$ & $3.347 \mathrm{~A}$ & $2.308 \mathrm{AC}$ \\
\hline Standard Deviation & \pm 0.68 & \pm 0.68 & \pm 0.92 & \pm 1.19 & \pm 1.49 & \pm 1.33 \\
\hline
\end{tabular}

Note: Different letters indicate statistically significant differences $(p<0.05)$. At least one equal letter indicates statistical similarity $(p>0.05)$. 
Table 5. Descriptive and inferential statistics of marginal leakage (mean and standard deviation in $\mathrm{mm}$ ).

\begin{tabular}{|c|c|c|c|c|c|c|}
\hline & $\begin{array}{l}\text { Etch-and-rinse } \\
\text { Halogen } \\
\quad(n=20)\end{array}$ & $\begin{array}{l}\text { Etch-and-rinse } \\
\text { LED } \\
(n=20)\end{array}$ & $\begin{array}{l}\text { Selective etching } \\
\text { Halogen } \\
(n=20)\end{array}$ & $\begin{array}{c}\text { Selective etching } \\
\text { LED } \\
(n=20)\end{array}$ & $\begin{array}{l}\text { Self-etch } \\
\text { Halogen } \\
(n=20)\end{array}$ & $\begin{array}{c}\text { Self-etch } \\
\text { LED } \\
(n=20)\end{array}$ \\
\hline Standard Deviation & \pm 0.68 & \pm 0.68 & \pm 0.92 & \pm 1.19 & \pm 1.49 & \pm 1.33 \\
\hline
\end{tabular}

Note: Different letters indicate statistically significant differences $(p<0.05)$. At least one equal letter indicates statistical similarity $(p>0.05)$.

The marginal leakage group comparison showed statistically significant difference among the groups $(p<0.0001)$ and the self-etching adhesive application mode presented more marginal leakage than etch-andrinse, especially when such adhesive application mode was used with the halogen light curing unit $(3.347 \mathrm{~mm})$. The combinations of etch-and-rinse showed, numerically, the lowest marginal leakages. The selective application mode presented intermediate results and, from the statistical point of view, it was similar to the other two application modes tested, except for the results of the halogenself-etching group and the LED-selective etching group, which showed statistical difference among the groups $(p<0.05)$.

\section{DISCUSSION}

More recently, a new category of adhesive systems was launched in the market, which may be used according to the specific clinical condition or the personal preference of the operator. These new adhesives were named universal or muti-mode adhesives, which means they are an evolution of the etch-and-rinse systems. The universal adhesives follow the "all-in-one" concept presented in the one-step self-etch adhesives. However, according to their manufacturers, these systems are versatile when applied to tooth structures using both the conventional and selfetching techniques. The manufacturers also suggest that universal adhesives may be used with the selective enamel etching technique [16]. A coupling mechanism occurs through the 10-MDP molecule, due to a micromechanical and chemical nanointeraction. Nanolayers of 10-MDP molecules form a stable salt known as MDP-Ca, which can make the adhesive interface more resistant to biodegradation. This may explain the clinical longevity documented for dentin interfaces, obtained from the use of adhesive systems containing such molecule [17].
Another aspect in the clinical decision-making is the type of light curing unit (halogen or LED), considering it is essential to photoactivate composite resins completely. Thus, with several potential combinations, a cost-benefit analysis is required to guide the options of dentists. These factors, added to the lack of studies in the literature associating type of light curing unit and adhesive application mode, guided the performance of the present study.

Regardless of the inherent limitations, this in vitro study was performed aiming to predict the clinical performance of the adhesive system used and to compare new products, analyzing the factors that could affect adhesion. Hence, the microtensile test was selected instead of other tests assessing bond strength, because it uses small-sized samples (approximately $1 \mathrm{~mm}^{2}$ ), leading to improved force distribution and lower probability of defects on the adhesive surface, which consequently leads to more realistic results [18]. Hamouda et al. have recommended a transverse section area of the resin-dentin interface from 0.8 to $1 \mathrm{~mm}^{2}$ to assess microtensile bond strength ( $\mu$ TBS) and the present study respected the area of $1 \mathrm{~mm}^{2}$. The literature has shown an inverse relationship between bond strength and bonding area, whereas the larger the area, the higher the resistance, considering that a small surface area of the specimen reduces the distribution of stresses, thus decreasing the number of internal defects that usually result only in adhesive failures [19].

Thermal cycling is the method mostly used for the aging of restorations and the durability assessment of materials in vitro. Although the oral cavity is the final environment for testing and predicting the behavior of restorations, the in vitro methods may simulate in vivo conditions [20]. The temperature variation between $5 \pm 1^{\circ} \mathrm{C}$ and $55 \pm 1^{\circ} \mathrm{C}$ is based on the knowledge that it represents the thermal variation of food intake during a meal. According to the ISO TR 11450 standard (1994), the specimens should be subjected to 500 thermal cycles 
of water between $5-55^{\circ} \mathrm{C}$ for the clinical simulation. However, there is no consensus in the literature regarding the number of cycles that should be used in the thermal cycling of materials [21]. The present study selected such aging method with 2000 cycles, because it is known that having too many cycles is not ideal for assessing composite resins. The selection of too many cycles may result in degradation due to higher thermal contraction, chemical degradation due to hot water accelerating the hydrolysis of the adhesive monomer, and stress in the resin-tooth structure interface due to fissure propagation along the interface [22].

The bond strength (BS) variable in dentin showed better results for the etch-and-rinse groups regardless of the type of light curing unit. The study by Alqahtani [23] supports the application of phosphoric acid in dentin before applying one-step self-etch adhesives, because of the significant improvements in bond strength. In the etchand-rinse adhesive systems, the phosphoric acid is applied at 35\% for 15 seconds in dentin, removing the smear layer and smear plugs, besides opening the dentinal tubules and demineralizing the intertubular dentin to a depth of $5 \mu \mathrm{m}$ approximately. Next, the one-bottle adhesive is applied and polymerized. In the self-etch version, as the monomer of the 10-MDP acid demineralizes the dentin surface, the other components of the adhesive are incorporated in the newly demineralized dentin. The adhesive systems containing 10-MDP are considered medium acidity, because this monomer presents a $\mathrm{pH}$ around 2, causing the partial demineralization of dentin and the formation of a lower hybrid layer of $1 \mu \mathrm{m}$. Thus, a study performed by Yoshida et al. [17], which involved scanning electron microscopy (SEM), showed the formation of a thicker hybrid layer and longer resin tags in the etch-and-rinse samples, when compared to the self-etch versions $[17,24]$.

The BS variable for enamel showed that the results for the etch-and-rinse groups were more effective than the universal system in the self-etch version. Enamel acid etching improves the bond strength values of adhesive systems according to the studies by Hanabusa et al. [25], which agrees with the results of the study by Nagpal et al. [26] that showed the previous phosphoric acid attack reducing the microleakage of self-etch adhesives. Studies suggest that the best bonding procedure should present previous acid etching followed by acid wash with water and enamel drying, even for self-etch adhesives [27].
Confirming the BS results, a higher number of cohesive failures was verified for the etch-and-rinse groups than for the self-etch groups, which in turn presented high rates of adhesive failures for both enamel and dentin, especially when using the LED light curing unit. Therefore, there was a direct relationship between the BS values found and the fracture patterns.

The microleakage results in both quantitative and qualitative analyses were superior in the etch-and-rinse mode when compared to the self-etching system, which agrees with the comparative study by Bader and Espinoza [28] with Single Bond Universal (SBU) (with and without acid etching) and Adper Single Bond 2. The SBU without acid etching and Adper Single Bond 2 did not present statistical differences for marginal microleakage, while SBU with previous acid etching presented lower marginal leakage values, which were significantly different and agreed with the study by Nagpal et al. [26] that showed the previous phosphoric acid attack reducing the microleakage of self-etch adhesives.

On the other hand, the restorations with selective etching showed similar results to etch-and-rinse, which may be explained by the use of phosphoric acid in enamel in both techniques. Some authors and even the manufacturers have been recommending such technique [29]. For Perdigão et al. [2], the selective enamel etching, when compared with self-etching, improved marginal integrity of the enamel in 18 months.

The behavior of the Single Bond Universal adhesive system and the different application modes are rather interesting from the clinical point of view. Even with the challenges in controlling moisture and depth of adhesive etching and leakage, the etch-and-rinse technique was effective when performed with criteria for controlling etching time, maintaining a moist dentin, and carefully applying the adhesive system. On the other hand, cases of deep dentin show potential postoperative sensitivity, and the universal system in the self-etching technique may be indicated with success for better results when associated with enamel etch-and-rinse [30].

The use of etch-and-rinse adhesive systems has been effective and longstanding for tooth enamel bonding, as the present study showed. However, the development and incorporation of new restorative materials and techniques require further studies to validate the application of such materials in the clinical practice. The use of LED, in turn, seems to be beneficial, considering 
it presents better enamel bond strength when combined with phosphoric acid etching. It also saves clinical time, considering that half of the photoactivation time provided results similar to the halogen light.

\section{CONCLUSION}

Based on the results of the present study, it may be concluded that, for enamel, the adhesive application with previous acid etching was better than self-etching, regardless of the type of light curing unit, while in dentin, the adhesive application with previous acid etching presented the highest bond strength values.

Moreover, etch-and-rinse showed the best results, presenting the lowest microleakage values when compared with self-etching, while the selective etching technique was efficient and did not differ from the etch-and-rinse technique.

The LED device presented microleakage similar to the halogen lamp.

\section{Collaborators}

FB RICARDI, author, idealizer, responsible for the development part, writing bond strength and marginal microleakage in the laboratory. MCA BUSATO and PMR BUSATO, co-authors, idealizers and guiding the research project. MJ MENDONÇA, responsible for interpretation of results and statistics. SV ROSA, laboratory assistant in bond strength and marginal microleakage tests. PB MARCHI, laboratory assistant in bond strength and marginal tests.

\section{REFERENCES}

1. Sezinando A. Looking for the ideal adhesive - a review. Rev Port Estomatol Med Med Dent. Cir Maxilofac. 2014; 55(1):194-206. https://doi.org/10.1016/j.rpemd.2014.07.004

2. Perdigão J, Kose C, Mena-Serrano AP, De Paula EA, Tay LY, Reis A. et al. A new universal simplified adhesive: 18-month clinical evaluation. Oper Dent. 2014;39(2):113-27. https://doi. org/10.2341/13-045-C

3. Reis $A F$, Giannini M, Pereira PN. Long-term TEM analysis of the nanoleakage patterns in resin-dentin interfaces produced by different bonding strategies. Dent Mater. 2007;23(9):1164-72. http://dx.doi.org/10.1016/j.dental.2006.10.006

4. Sekhri S, Mittal S, Garg S. Tensile Bond Strength of Self Adhesive Resin Cement After Various Surface Treatment of Enamel. J Clin Diagn Res. 2016; 10(1):01-04. http://doi. org/10.7860/JCDR/2016/13409.7026
5. Alex G. Universal adhesives: the next evolution in adhesive dentistry? Compend Contin Educ Dent. 2015 ;36(1):15-26.

6. Kim RJ, Woo J, Lee I, Yi Y, Hwang J, Seo D. Performance of universal adhesives on bonding to leucite-reinforced ceramic. Biomat Resear. 2015; 19(1): 1-6. https://doi.org/10.1186/s40 824-015-0035-1

7. Sabatini C. Comparative study of surface microhardness of methacrylate-based composite resins polymerized with lightemitting diodes and halogen. 2013; 7(3):327-35. http://doi. org/10.4103/1305-7456.115417

8. Zakavi F, Golpasand Hagh L, Sadeghian S, Freckelton $V$, Daraeighadikolaei A, Ghanatir E, et al. Evaluation of microleakage of class II dental composite resin restorations cured with LED or QTH dental curing light; Blind, Cluster Randomized, In vitro cross sectional study. BMC Res Notes. 2014;3(7):416. https://doi.org/10.1186/1756-0500-7-416

9. Karaman E, Gonulol N. Does the light source affect the repairability of composite resins? Braz Oral Res. 2014;28(1): 327-335. http://dx.doi.org/10.1590/1807-3107BOR-2014.vol28. 0027

10. Bhalla M, Patel D, Shashikiran ND, Mallikarjuna RM, Nalawade TM, Reddy HK. Effect of light-emitting diode and halogen light curing on the micro-hardness of dental composite and resin-modified glass ionomer cement: an in vitro study. J Indian Soc Pedod Prev Dent. 2012; 30(3):201-5. https://doi. org/10. 4103/0970-4388.105011

11. Muñoz MA, Luque I, Hass V, Reis A, Loguercio AD, Bombarda $\mathrm{NH}$. Immediate bonding properties of universal adhesives to dentine. J Dent. 2013; 41(5):404-11. https://doi.org/10.1016/j. jdent.2013.03.001

12. Busato PMR, Loguercio $A D$, Gonini Júnior $A$, Lopes $M B$, Moura SK. Selamento Marginal da União Adesivo/Dentina em Função da Técnica de Evaporação de Solventes. UNOPAR Cient. 2010;12(1):39-44. http://dx.doi.org/10.17921/2447-8 938.2010v12n1p\%25p

13. International Organization for Standardization (ISO) / Technical Report (TR) 11405: Dental Materials - Guidance on testing of adhesion to tooth structure; 1994.

14. Sivakumar JSK, Prasad AS, Soundappan S, Ragavendran N, Ajay R, Santham K. A comparative evaluation of microleakage of restorations using silorane-based dental composite and methacrylate-based dental composites in Class II cavities: An in vitro study. Journal of Pharmacy \& Bioallied Sciences. 2016; 8(1):81-5. http://doi.org/10.4103/0975-7406.191975

15. De Santi AFA, Pinelli C, Monteiro LLC. Reliability of marginal microleakage assessment by visual and digital methods. European Journal of Dentistry. 2015; 9(1): 1-5. http://doi.org/10. 4103/1305-7456.149628

16. Wagner A, Wendler M, Petschelt A, Belli R, Lohbauer U. Bonding performance of universal adhesives in different etching modes. J Dent. 2014; 42(7):800-7. https://doi.org/10.10 16/j.jdent.2014.04.012

17. Yoshida Y, Yoshihara K, Nagaoka N, Hayakawa S, Torii Y, Ogawa $T$, et al. Self-assembled nano-layering at the adhesive interface. J Dent Res. 2012; 91(4):376-81 https://doi.org/10. $1177 / 0022034512437375$ 
18. Hamouda IM, Samra NR, \& Badawi MF. Microtensile bond strength of etch and rinse versus self-etch adhesive systems. J Mech Beh Biom Mat. 2011; 4(3):461-6. https://doi.org/10. 1016/j.jmbbm.2010.12.007

19. Taneja S, Kumar P, Kumar A. Comparative evaluation of the microtensile bond strength of bulk fill and low shrinkage composite for different depths of Class II cavities with the cervical margin in cementum: An in vitro study. J Cons Dent. 2016; 19(6): 532-5. http://doi.org/10.4103/0972-070 7.194023

20. Kasraei S, Yarmohammadi E, Ghazizadeh MV. Microshear Bond Strength of OptiBond All-in-One Self-adhesive Agent to Er: YAG Laser Treated Enamel After Thermocycling and Water Storage. J Las Med Scie. 2016; 7(3):152-8. http://doi. org/10.15171/jlms.2016.26

21. Morresi AL, D'Amario M, Capogreco M, Gatto R, Marzo G, $D^{\prime}$ Arcangelo $C$. et al. Thermal cycling for restorative materials: does a standardized protocol exist in laboratory testing? A literature review. J Mech Behav Biomed Mater. 2014; 29(1):295-308. https://doi.org/10.1016/j.jmbbm.2013.09.013

22. Sangwichit K, Kingkaew R, Pongprueksa P, Senawongse P. Effect of thermocycling on the durability of etch-and-rinse and self-etch adhesives on dentin. Dent Mater J. $2016 \mathrm{Jul}$; 35(3): 360-8. https://doi.org/10.4012/dmj.2015-253

23. Alqahtani MQ. Influence of acid-etching or double-curing time on dentin bond strength of one-step self-etch adhesive. Saudi J Dent Res. 2015; 6(2): 110-6. https://doi.org/10.1016/j. sjdr.2014.12.002

24. Neelima L, Sathish ES, Kandaswamy D; Bupesh. Evaluation of microtensile bond strength of total-etch, self-etch, and glass ionomer adhesive to human dentin: an in vitro study. Indian J Dent Res. 2008; 19(2):129-33. https://doi.org/10.4103/0970-92 90.40467
25. Hanabusa M, Mine A, Kuboki T, Momoi Y, Van Ende A, Van Meerbeek B. et al. Bonding effectiveness of a new "multi mode" adhesive to enamel and dentin. J Dent. 2012; 40(6): 475-84. doi: 10.1016/ j.jdent.2012.02.012

26. Nagpal R, Manuja N, Tyagi SP, Singh UP. In vitro bonding effectiveness of self-etch adhesives with different application techniques: A microleakage and scanning electron microscopic study. J Cons Dent. 2011; 14(3):258-263. doi: 10.4103/0972-0 707.85805

27. Van Meerbeek B, Yoshiara K. Yoshida Y, Mine A, De Munch J, Van Landuyt KL. State of the art of self-etch adhesives. Dent Mater. 2011; 27(1): 17-28. http://dx.doi.org/10.1016/j. dental.2010.10.023

28. Bader M, Espinoza T. Análisis comparativo in vitro del grado de filtración marginal de restauraciones de resina compuesta realizadas utilizando el sistema adhesivo Adper ${ }^{\text {TM }}$ Single bond 2 con grabado ácido y Single Bond ${ }^{\mathrm{TM}}$ Universal con y sin grabado ácido. Rev Biomater Sociedad científica Grupo Chileno de Materiales Dentales. 2015; 2(1): 50-69.

29. Loguercio AD, Muñoz MA, Luque-Martinez I, Hass V, Reis $A$, Perdigão J. Does active application of universal adhesives to enamel in self-etch mode improve their performance? J Dent. 2015; 43(9):1060-70. https://doi.org/10.1016/j.jdent. 2015.04.005

30. Sahin C, Cehreli ZC, Yenigul H, Dayangac B. In vitro permeability of etch-and-rinse and self-etch adhesives used for immediate dentin sealing. J Dent Mater. 2012; 31(3):401-8. https://doi.org/10.4012/dmj.2011-217

Received on: $27 / 6 / 2018$

Final version resubmitted on: 31/10/2018 Approved on: 30/11/2018 